\title{
BMJ Open Key factors of case management interventions for frequent users of healthcare services: a thematic analysis review
}

\author{
Catherine Hudon, ${ }^{1,2}$ Maud-Christine Chouinard, ${ }^{3,4}$ Mireille Lambert, ${ }^{4}$ \\ Fatoumata Diadiou, ${ }^{4}$ Danielle Bouliane, ${ }^{4}$ Jérémie Beaudin ${ }^{3}$
}

To cite: Hudon C,

Chouinard M-C, Lambert M, et al. Key factors of case management interventions for frequent users of healthcare services: a thematic analysis review. BMJ Open 2017;7:e017762. doi:10.1136/ bmjopen-2017-017762

\section{- Prepublication history for} this paper is available online. To view these files please visit the journal online (http://dx.doi org/10.1136/bmjopen-2017017762).

Received 15 May 2017 Revised 11 September 2017 Accepted 15 September 2017

\section{CrossMark}

${ }^{1}$ Department of Family Medicine and Emergency Medicine, Université de Sherbrooke, Sherbrooke, Quebec, Canada ${ }^{2}$ Centre de recherche du Centre Hospitalier, Universitaire de Sherbrooke, Sherbrooke, Quebec, Canada

${ }^{3}$ Département des Sciences de la santé, Université du Québec à Chicoutimi, Chicoutimi, Quebec, Canada

${ }^{4}$ Centre integre universitaire de sante et de services sociaux du Saguenay-Lac-Saint-Jean, Chicoutimi, Quebec, Canada

Correspondence to Professor Catherine Hudon; catherine.hudon@usherbrooke. ca

\section{ABSTRACT}

Objective The aim of this paper was to identify the key factors of case management (CM) interventions among frequent users of healthcare services found in empirical studies of effectiveness.

Design Thematic analysis review of CM studies.

Methods We built on a previously published review that aimed to report the effectiveness of CM interventions for frequent users of healthcare services, using the Medline, Scopus and CINAHL databases covering the January 2004-December 2015 period, then updated to July 2017, with the keywords 'CM' and 'frequent use'. We extracted factors of successful $(n=7)$ and unsuccessful $(n=6)$ CM interventions and conducted a mixed thematic analysis to synthesise findings. Chaudoir's implementation of health innovations framework was used to organise results into four broad levels of factors: (1) ,environmental/ organisational level, (2) practitioner level, (3) patient level and (4) programme level.

Results Access to, and close partnerships with, healthcare providers and community services resources were key factors of successful CM interventions that should target patients with the greatest needs and promote frequent contacts with the healthcare team. The selection and training of the case manager was also an important factor to foster patient engagement in CM. Coordination of care, self-management support and assistance with care navigation were key $\mathrm{CM}$ activities. The main issues reported by unsuccessful CM interventions were problems with case finding or lack of care integration.

Conclusions CM interventions for frequent users of healthcare services should ensure adequate case finding processes, rigorous selection and training of the case manager, sufficient intensity of the intervention, as well as good care integration among all partners. Other studies could further evaluate the influence of contextual factors on intervention impacts.

\section{INTRODUCTION}

Frequent users of healthcare services are a small group of patients accounting for a high number of healthcare visits, often emergency department (ED), and important costs. ${ }^{1-3}$
Strengths and limitations of this study

- The 13 studies included in this paper were identified by a rigorous search strategy used in a previous review of case management (CM) interventions for frequent users of healthcare services.

- Material from qualitative studies was not included in the analysis.

- Little description of CM interventions was provided in the included studies.

They use healthcare services for complex health needs, ${ }^{4-6}$ combining multiple chronic conditions with psychosocial or mental health comorbidities. ${ }^{578}$ Frequent use of services is often considered inappropriate ${ }^{79}$ and may be a symptom of gaps in accessibility and coordination of care. ${ }^{10} 11$ These patients are more at risk for incapacity, poorer quality of life and mortality. ${ }^{12-15}$ Regardless of healthcare setting, case management (CM) is the most frequently implemented intervention to improve care for frequent users of healthcare services and to reduce healthcare usage and cost. $^{1617}$

$\mathrm{CM}$ is a 'collaborative process of assessment, planning, facilitation and advocacy for options and services to meet an individual's health needs through communication and available resources to promote quality cost-effective outcomes'. ${ }^{18}$ Reviews reported positive outcomes associated with CM interventions among frequent users of healthcare services such as decreases in ED use and cost. ${ }^{1617}$ 19-21 They also concluded that $\mathrm{CM}$ interventions resulted in a better use of appropriate existing resources ${ }^{22}$ and a reduction in social problems such as homelessness and drug and alcohol abuse. ${ }^{22-24}$

A small number of systematic reviews briefly addressed enabling factors of successful CM interventions in the discussion section 
of their paper. In a review on the effectiveness of CM among frequent ED users, Kumar and Klein ${ }^{19}$ noted that frequency of follow-up, availability of psychosocial services, assistance with financial issues and active engagement of the case manager and the patient were important characteristics of CM interventions. Oeseburg et $a l^{25}$ evaluated the effects of CM for frail older people (not necessarily frequent users) and highlighted that well-trained case managers with competent skills in designing care plans and coordinating services, effective communication and collaboration between the members of the healthcare team, as well as the acceptance of the case manager as the coordinator for care delivery, were key factors of CM. However, the identification of key factors of CM interventions was not a primary objective of these reviews, although this information would be useful to inform researchers and decision makers on the implementation of $\mathrm{CM}$.

The aim of this paper was to identify the key factors of CM interventions among frequent users of healthcare services found in empirical studies of effectiveness.

\section{METHODS}

We first conducted a scoping review that aimed to report the effectiveness of CM for frequent users of healthcare services, using the Medline, Scopus and CINAHL databases covering the January 2004-December 2015 period, with the keywords ' $\mathrm{CM}$ ' and 'frequent use'. ${ }^{20}$ To be included in the review, studies had to report on the effects of a CM intervention on healthcare usage and/ or cost. We excluded studies limited to a specific group of patients and interventions targeting a single disease. The review included 11 articles and concluded that CM could reduce healthcare use and cost. A detailed description of the articles included and the CM interventions is provided in the published review. ${ }^{20}$ For the purpose of this paper, the search strategy was updated to July 2017, therefore, two additional articles were added (figure 1), for a total of 13 studies.

We then extracted factors of successful $(n=7)$ and unsuccessful $(n=6) \quad C M$ interventions to conduct a mixed thematic analysis to synthesise findings across the studies $^{26-28}$ using a framework proposed by Chaudoir et $a .^{29}$ This framework was developed to reflect factors hypothesised to impact outcomes and was used to capture the characteristics of $\mathrm{CM}$ interventions, while allowing comparisons among the studies included. According to this framework, the relevant factors were organised into four broad levels to address in the implementation of a health innovation: (1) environmental/organisational level: setting and structure in which $\mathrm{CM}$ is being implemented, including physical environmental, public

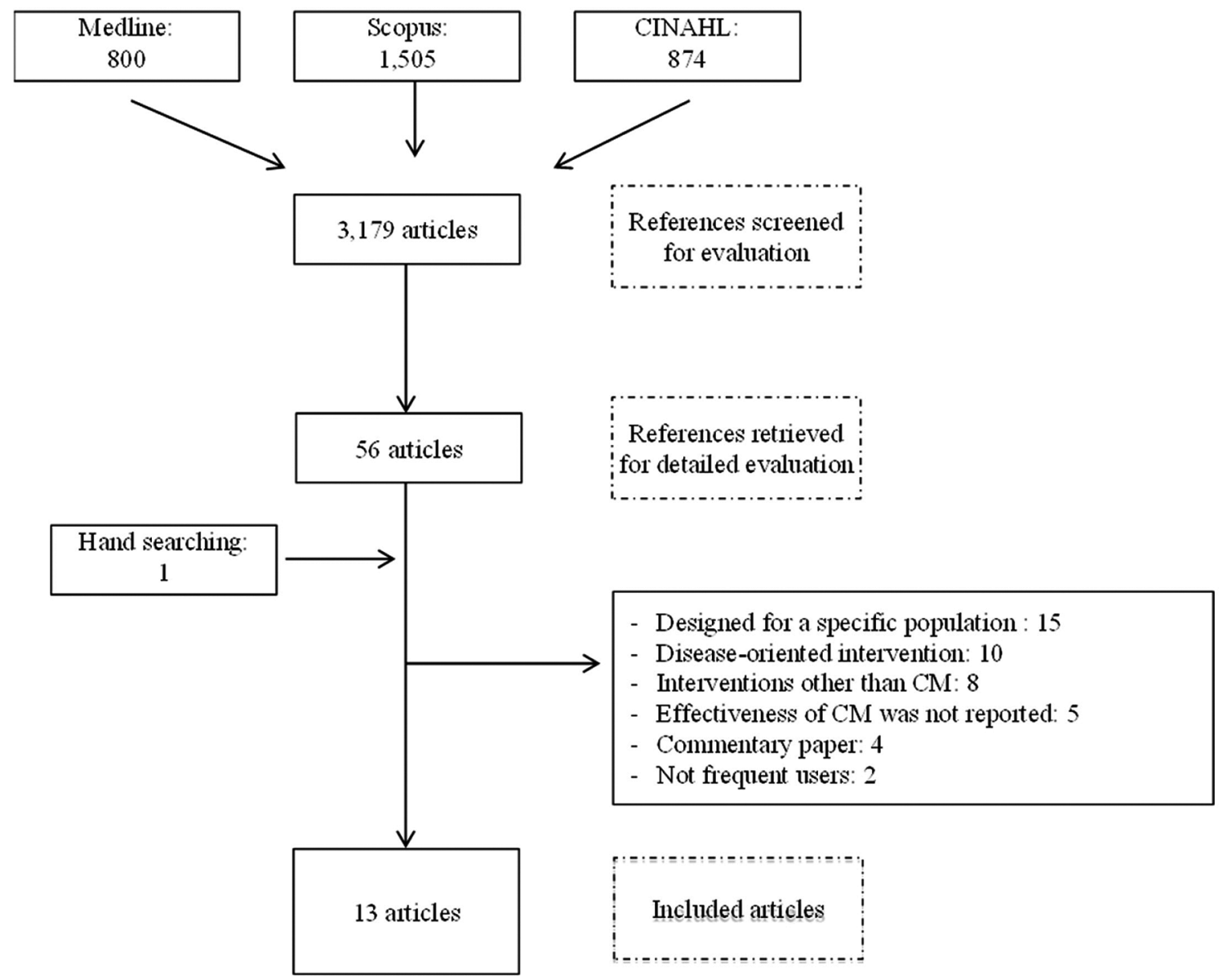

Figure 1 Scoping review flow chart of search results (2004-July 2017). CM, case management. 


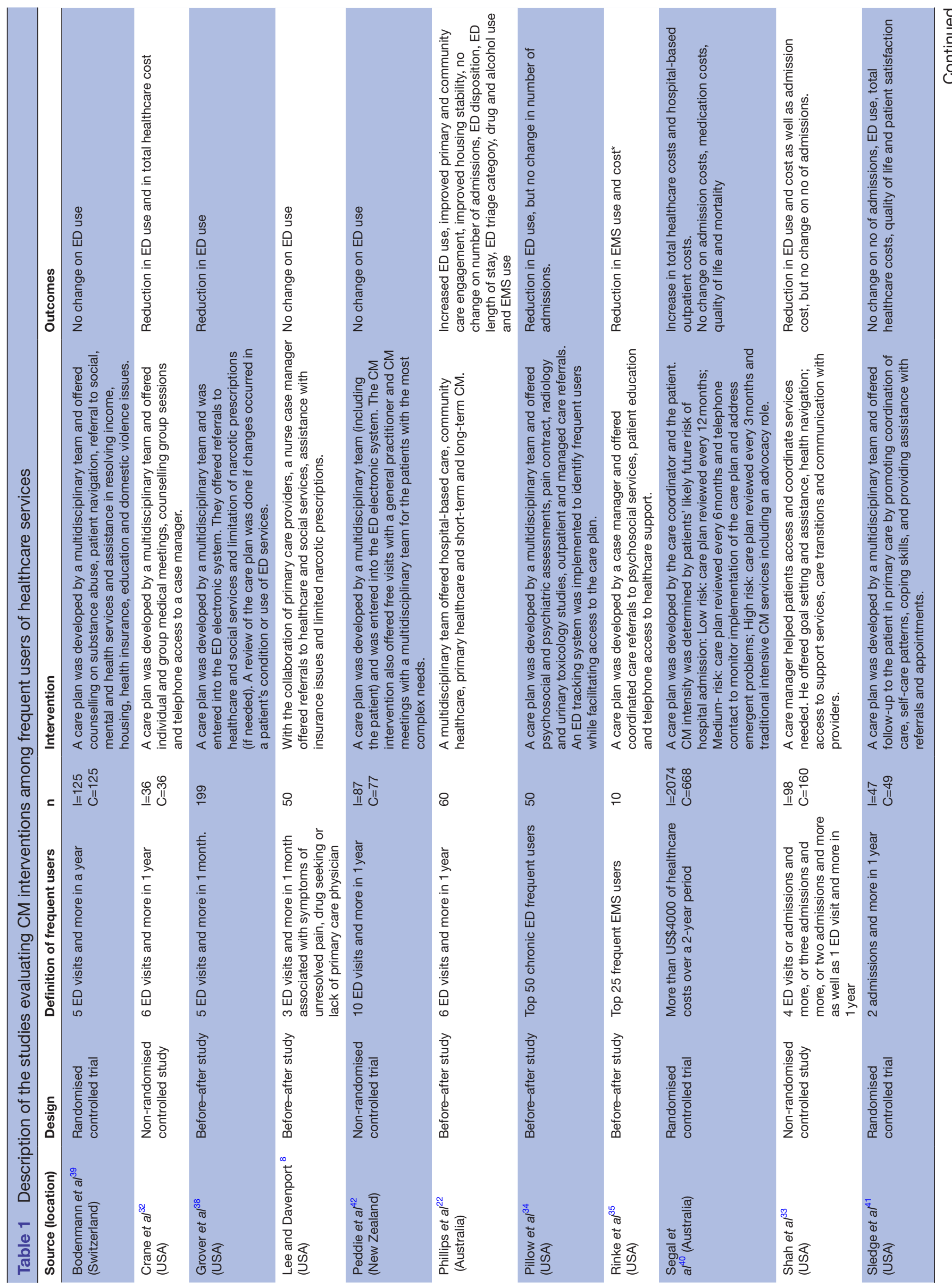


policies, infrastructures, economical, political and social contexts and different features of the organisation (eg, leadership effectiveness, organisational culture and staff satisfaction towards the organisation); (2) practitioner level: characteristics and experience of the provider who is in contact with patients for the purpose of CM, including attitudes and beliefs towards CM, professional role and capacities; (3) patient level: characteristics and experience of the patient, including motivation, perception, personality traits, risk factors, skills and abilities and (4) programme level: aspects of $\mathrm{CM}$, including characteristics and activities (evaluation, patient education, self-management support, referrals, transition, etc) as well as compatibility of the intervention with the organisation and adaptability. ${ }^{29-31}$

\section{RESULTS}

\section{Description of the studies}

The 13 studies are described in table 1 . Seven studies (two non-randomised controlled studies ${ }^{32}{ }^{33}$ and five before-after studies ${ }^{34-38}$ ) reported positives outcomes on healthcare usage or cost. Wetta-Hall ${ }^{37}$ evaluated a multidisciplinary CM intervention among frequent ED users and demonstrated a decrease in ED use as well as an improvement in physical quality of life. Crane $e t a l^{2}$ assessed a multidisciplinary $\mathrm{CM}$ intervention including a care plan among frequent ED users and observed a decrease in ED use and healthcare cost. Shah et a $\hat{l}^{33}$ conducted a study with low-income, uninsured patients on the implementation of a care plan by a case manager and demonstrated that ED use, as well as cost, had significantly decreased. Pillow $e t a l^{34}$ conducted a before-after study with the top ED frequent users to measure the impact of a multidisciplinary CM intervention including a care plan and reported a trend towards a decrease in ED use. Rinke $e t a \vec{l}^{35}$ in a study evaluating the impact of the implementation of a care plan by a case manager for the most frequent emergency medical services (EMS) users, as well as Tadros $e t a l,{ }^{36}$ in a study evaluating a $\mathrm{CM}$ intervention conducted by a case manager among frequent EMS users, observed a decrease in EMS cost and use. Finally, Grover $e t a l^{88}$ evaluated the effectiveness of a multidisciplinary CM intervention including a care plan among frequent ED users and reported a reduction in ED use and radiation exposure, improved efficacy of referral, but no change in number of admissions.

Six studies reported no benefit on healthcare usage or cost, including three randomised controlled trials, ${ }^{39-41}$ two before-after studies ${ }^{82}$ and one non-randomised controlled study. ${ }^{42}$ The study by Bodenmann $e t a l^{39}$ on the effectiveness of a multidisciplinary CM intervention including a care plan and the pilot study by Lee and Davenport $^{8}$ on a nurse CM intervention reported no change on ED use. Peddie $e t a t^{42}$ came to the same conclusion in a study evaluating the impact of a management plan on the frequency of ED visits. Sledge $e t a l^{11}$ conducted a study to evaluate a clinic-based ambulatory CM intervention and 


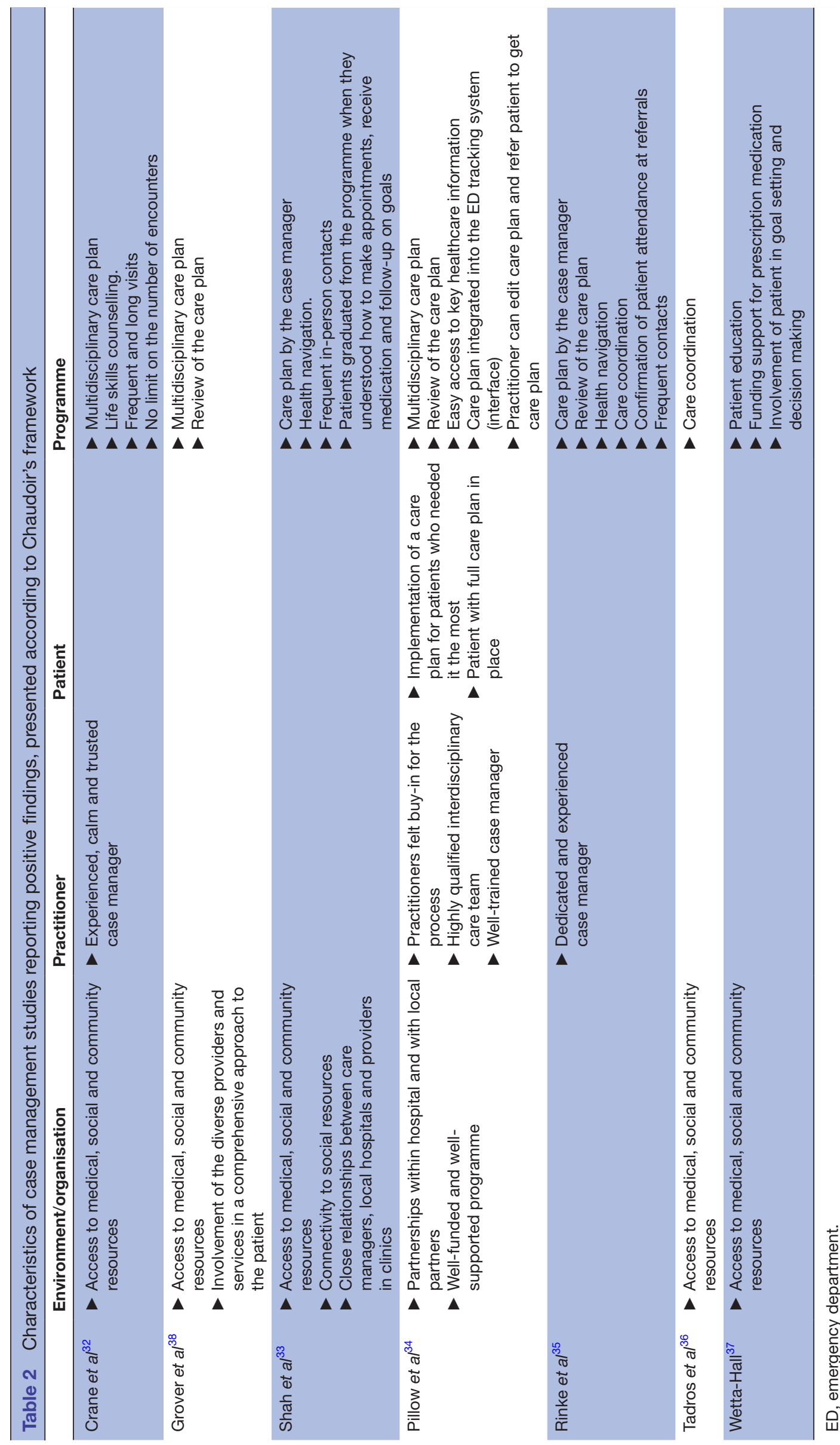


reported no significant change on number of admissions, ED use, total healthcare cost, quality of life and patient satisfaction. In a study evaluating the effectiveness of multidisciplinary CM, Phillips $e t a l^{22}$ observed an increase in ED use and no change on admissions. Similarly, in a study on a care coordination programme including care planning by a general practitioner and CM intervention, Segal $e t a t^{40}$ reported an increase in total healthcare and outpatient costs and no change on admissions and medication costs, as well as quality of life.

\section{Key factors of CM intervention}

Successful and unsuccessful factors of CM interventions are shown in tables 2 and 3, classified according to Chaudoir et $a l{ }^{29} \mathrm{~s}^{29}$ framework.

Most authors reported that access to, and close relationships between, case managers and their partners (healthcare providers at the hospital and clinics, staff from community organisations, etc) were key factors of $\mathrm{CM}$ interventions as well as engagement and involvement of healthcare and community partners. ${ }^{8} 333438$ Two studies reported lack of collaboration between the case manager and primary care providers and lack of integration into a systemic approach to care as major flaws. ${ }^{841}$

The selection and training of the case manager was also mentioned as a key factor. A dedicated, trusting and experienced case manager could improve patient engagement in CM and foster better patient involvement in self-management. ${ }^{32} 3435$ Conversely, authors of two studies highlighted the difficulty of finding a well-trained case manager as a main limitation of their study. ${ }^{22}{ }^{41}$ Engagement of the case manager, as well as all the healthcare providers involved in the intervention, and their capacity to motivate the patient were also important, highlighting the need of having practitioners who feel buy-in in regard to the intervention. ${ }^{34}$

Pillow $e t a l^{34}$ emphasised the importance of recruiting patients with greatest needs, namely very high ED users with complex healthcare needs. In three studies that did not demonstrate benefit, many patients did not have complex needs and/or were not the highest users of healthcare services, ${ }^{3940}$ or had substance abuse or psychosocial issues without a chronic condition. ${ }^{22}$

Coordination of care, ${ }^{35} 36$ patient education and self-management support, ${ }^{82-34}$ and assistance to navigate in the healthcare system ${ }^{33} 35$ were key activities of successful CM interventions. Most of the studies included a care plan based on an evaluation of patient needs; five observed a reduction in healthcare use, ${ }^{32-35} 38$ whereas four reported no benefit. ${ }^{39-42}$ Revision of the care plan by a multidisciplinary team during the CM intervention, in response to a better understanding of patient needs or to a change in patient health condition seemed an important factor. ${ }^{34358}$ Frequent contacts with the patient, either by telephone or in person, were also useful. $^{2333} 35$ 


\section{DISCUSSION}

This paper is the first thematic analysis review synthesising key factors of CM interventions among frequent users of healthcare services. Access to, and close partnerships with, healthcare providers and community services resources were key factors of CM interventions that should target patients with the greatest needs and promote frequent contacts with the healthcare team. The selection and training of the case manager was also an important factor to consider in order to foster patient engagement in CM. Coordination of care, self-management support and assistance with care navigation were key CM activities. The main issues with unsuccessful CM interventions were problems in case finding or lack of care integration.

In a series of reports from The King's Fund about the implementation of CM for people with long-term conditions, Ross $e t a t^{43}$ stressed the role and skills of the case manager, appropriate case finding and caseload, single point of access for patients, continuity of care, self-management support, interprofessional collaboration and development of information systems for the effective use of data and communication processes. Convergent findings were reported in a synthesis by Berry-Millett and Bodenheimer ${ }^{44}$ that aimed to examine the impact of CM to improve care and reduce healthcare costs for frequent users with complex needs. They identified six factors of successful CM, namely selecting high-risk patients, promoting face-to-face meetings, training case managers with low caseloads, creating multidisciplinary teams where physicians and case managers work in the same location, involving peers and promoting self-management skills. Our review, which aimed to identify key factors of CM as a primary objective, corroborates and completes these results, by a rigorous thematic analysis of 13 empirical studies on the topic.

As already noted by other authors, ${ }^{45}$ context description was lacking in most studies. As a complex intervention, CM includes various components interacting in a nonlinear way to produce outcomes that are highly dependent on context and variables across settings. ${ }^{46} 47$ Special attention should be paid to contextual factors of CM. Indeed, further studies could analyse not only if and how CM works for frequent users of healthcare services but also in what contexts.

\section{LIMITATIONS}

Description of CM interventions was a limit of many studies included. According to the International Classification of Health Interventions, ${ }^{48}$ the coordination target for what was done was different in the studies. Including material from qualitative studies could enrich results in further steps.

\section{CONCLUSIONS}

CM interventions for frequent users of healthcare services should ensure adequate case-finding processes, rigorous selection and training of the case manager, sufficient intensity of the intervention and good care integration among all partners. Other studies could further evaluate the influence of contextual factors on intervention impacts.

Acknowledgements The authors thank Ms Susie Bernier for her editorial assistance.

Contributors $\mathrm{CH}$ and $\mathrm{M}-\mathrm{CC}$ developed the study and participated in its design and coordination. ML conducted the data collection and drafted the manuscript under the supervision of $\mathrm{CH}$ and $\mathrm{M}-\mathrm{CC}$. All authors were involved in drafting and editing the manuscript.

Competing interests All authors have completed the ICMJE uniform disclosure form at www.icmje.org/coi_disclosure.pdf and declare: no support from any organisation for the submitted work; no financial relationships with any organisations that might have an interest in the submitted work in the previous three years; no other relationships or activities that could appear to have influenced the submitted work.

Patient consent None.

Provenance and peer review Not commissioned; externally peer reviewed.

Open Access This is an Open Access article distributed in accordance with the Creative Commons Attribution Non Commercial (CC BY-NC 4.0) license, which permits others to distribute, remix, adapt, build upon this work non-commercially, and license their derivative works on different terms, provided the original work is properly cited and the use is non-commercial. See: http://creativecommons.org/ licenses/by-nc/4.0/

(c) Article author(s) (or their employer(s) unless otherwise stated in the text of the article) 2017. All rights reserved. No commercial use is permitted unless otherwise expressly granted.

\section{REFERENCES}

1. Bodenheimer T, Berry-Millett R. Follow the money--controlling expenditures by improving care for patients needing costly services. N Engl J Med 2009;361:1521-3.

2. Commission on the Reform of Ontario's Public Services. Public services for Ontarians: a path to sustainability and excellence. Ottawa: Queen's Printer for Ontario, 2012.

3. LaCalle E, Rabin E. Frequent users of emergency departments: the myths, the data, and the policy implications. Ann Emerg Med 2010;56:42-8.

4. Hansagi H, Olsson M, Sjöberg S, et al. Frequent use of the hospital emergency department is indicative of high use of other health care services. Ann Emerg Med 2001;37:561-7.

5. Chan BT, Ovens HJ. Frequent users of emergency departments. Do they also use family physicians' services? Can. Fam. Physician 2002;48:1654-60.

6. Byrne M, Murphy AW, Plunkett PK, et al. Frequent attenders to an emergency department: a study of primary health care use, medical profile, and psychosocial characteristics. Ann Emerg Med 2003;41:309-18.

7. Ruger JP, Richter CJ, Spitznagel EL, et al. Analysis of costs, length of stay, and utilization of emergency department services by frequent users: implications for health policy. Acad Emerg Med 2004;11:1311-7.

8. Lee $\mathrm{KH}$, Davenport L. Can case management interventions reduce the number of emergency department visits by frequent users? Health Care Manag 2006;25:155-9.

9. Murphy AW, Leonard C, Plunkett PK, et al. Characteristics of attenders and their attendances at an urban accident and emergency department over a one year period. J Accid Emerg Med 1999;16:425-7.

10. Lowe RA, Localio AR, Schwarz DF, et al. Association between primary care practice characteristics and emergency department use in a medicaid managed care organization. Med Care 2005;43:792-800.

11. Haggerty JL, Roberge D, Pineault R, et al. Features of primary healthcare clinics associated with patients' utilization of emergency rooms: urban-rural differences. Healthc Policy 2007;3:72-85.

12. Fuda KK, Immekus R. Frequent users of Massachusetts emergency departments: a statewide analysis. Ann Emerg Med 2006;48:16. e1-16.e8. 
13. Browne GB, Humphrey B, Pallister R, et al. Prevalence and characteristics of frequent attenders in a prepaid Canadian family practice. J Fam Pract 1982;14:63-71.

14. Hansagi $\mathrm{H}$, Allebeck $\mathrm{P}$, Edhag $\mathrm{O}$, et al. Frequency of emergency department attendances as a predictor of mortality: nine-year follow-up of a population-based cohort. J Public Health Med 1990;12:39-44.

15. Kersnik J, Svab I, Vegnuti M. Frequent attenders in general practice: quality of life, patient satisfaction, use of medical services and GP characteristics. Scand J Prim Health Care 2001;19:174-7.

16. Althaus F, Paroz S, Hugli O, et al. Effectiveness of interventions targeting frequent users of emergency departments: a systematic review. Ann Emerg Med 2011;58:41-52.

17. Soril LJ, Leggett LE, Lorenzetti DL, et al. Reducing frequent visits to the emergency department: a systematic review of interventions. PLoS One 2015;10:e0123660.

18. Case Management Society of America. What is a case manager? http://www.cmsa.org/Home/CMSA/WhatisaCaseManager/tabid/224/ Default.aspx

19. Kumar GS, Klein R. Effectiveness of case management strategies in reducing emergency department visits in frequent user patient populations: a systematic review. J Emerg Med 2013;44:717-29.

20. Hudon C, Chouinard MC, Lambert M, et al. Effectiveness of case management interventions for frequent users of healthcare services: a scoping review. BMJ Open 2016;6:e012353.

21. Stokes J, Panagioti M, Alam R, et al. Effectiveness of case management for 'At Risk' patients in primary care: a systematic review and meta-analysis. PLoS One 2015;10:e0132340.

22. Phillips GA, Brophy DS, Weiland TJ, et al. The effect of multidisciplinary case management on selected outcomes for frequent attenders at an emergency department. Med J Aust 2006;184:602-6.

23. Okin RL, Boccellari A, Azocar F, et al. The effects of clinical case management on hospital service use among ED frequent users. Am J Emerg Med 2000;18:603-8.

24. Shumway M, Boccellari A, O'Brien K, et al. Cost-effectiveness of clinical case management for ED frequent users: results of a randomized trial. Am J Emerg Med 2008;26:155-64.

25. Oeseburg B, Wynia K, Middel B, et al. Effects of case management for frail older people or those with chronic illness: a systematic review. Nurs Res 2009;58:201-10.

26. Mays N, Pope C, Popay J. Systematically reviewing qualitative and quantitative evidence to inform management and policy-making in the health field. J Health Serv Res Policy 2005;10:6-20.

27. Kastner M, Tricco AC, Soobiah C, et al. What is the most appropriate knowledge synthesis method to conduct a review? Protocol for a scoping review. BMC Med Res Methodol 2012;12:114.

28. Miles MB, Huberman AM, Saldaña J. Qualitative Data Analysis: A methods sourcebook. 3rd ed. London: Sage Publications Inc, 2014.

29. Chaudoir SR, Dugan AG, Barr CH. Measuring factors affecting implementation of health innovations: a systematic review of structural, organizational, provider, patient, and innovation level measures. Implement Sci 2013;8:22.

30. Durlak JA, DuPre EP. Implementation matters: a review of research on the influence of implementation on program outcomes and the factors affecting implementation. Am J Community Psychol 2008;41:327-50.

31. Damschroder LJ, Aron DC, Keith RE, et al. Fostering implementation of health services research findings into practice: a consolidated framework for advancing implementation science. Implement Sci 2009;4:50.

32. Crane $\mathrm{S}$, Collins L, Hall J, et al. Reducing utilization by uninsured frequent users of the emergency department: combining case management and drop-in group medical appointments. J Am Board Fam Med 2012;25:184-91.

33. Shah R, Chen C, O'Rourke S, et al. Evaluation of care management for the uninsured. Med Care 2011;49:166-71.

34. Pillow MT, Doctor S, Brown S, et al. An Emergency Departmentinitiated, web-based, multidisciplinary approach to decreasing emergency department visits by the top frequent visitors using patient care plans. J Emerg Med 2013;44:853-60.

35. Rinke ML, Dietrich E, Kodeck T, et al. Operation care: a pilot case management intervention for frequent emergency medical system users. Am J Emerg Med 2012;30:352-7.

36. Tadros AS, Castillo EM, Chan TC, et al. Effects of an emergency medical services-based resource access program on frequent users of health services. Prehosp Emerg Care 2012;16:541-7.

37. Wetta-Hall R. Impact of a collaborative community case management program on a low-income uninsured population in Sedgwick County, KS. Appl Nurs Res 2007;20:188-94.

38. Grover CA, Crawford E, Close RJ. The efficacy of case management on emergency department frequent users: An Eight-Year Observational Study. J Emerg Med 2016;51:595-604.

39. Bodenmann P, Velonaki VS, Griffin JL, et al. Case management may reduce emergency department frequent use in a universal health coverage system: a randomized controlled trial. J Gen Intern Med 2017;32:508-15.

40. Segal L, Dunt D, Day SE, et al. Introducing co-ordinated care (1): a randomised trial assessing client and cost outcomes. Health Policy 2004;69:201-13.

41. Sledge WH, Brown KE, Levine JM, et al. A randomized trial of primary intensive care to reduce hospital admissions in patients with high utilization of inpatient services. Dis Manag 2006;9:328-38.

42. Peddie S, Richardson S, Salt L, et al. Frequent attenders at emergency departments: research regarding the utility of management plans fails to take into account the natural attrition of attendance. N Z Med J 2011;124:61-6.

43. Ross S, Curry N, Goodwin N. Case Management: What it is and how it can best be implemented. London, UK: The King's Funds, 2011.

44. Berry-Millett R, Bodenheimer TS. Care management of patients with complex health care needs. Synth Proj Res Synth Rep 2009.

45. Petticrew M, Rehfuess E, Noyes J, et al. Synthesizing evidence on complex interventions: how meta-analytical, qualitative, and mixed-method approaches can contribute. J Clin Epidemiol 2013;66:1230-43.

46. Shepperd S, Lewin S, Straus S, et al. Can we systematically review studies that evaluate complex interventions? PLoS Med 2009;6:e1000086.

47. Pawson R. Nothing as Practical as a Good Theory. Evaluation 2003:9:471-90.

48. ICHI. ICHI Alpha 2016. https://mitel.dimi.uniud.it/ichi/\# 